\title{
Palmitic and linoleic acids induce ER stress and apoptosis in hepatoma cells
}

Yong Zhang ${ }^{1}$, Rongliang Xue ${ }^{1 *}$, Zhenni Zhang ${ }^{1}$ Xia Yang ${ }^{2}$ and Hongyang Shi ${ }^{2}$

\begin{abstract}
Objectives: Hepatic inflammation and degeneration induced by lipid depositions may be the major cause of nonalcoholic fatty liver disease. In this study, we tried to investigate the effects of saturated and unsaturated fatty acids on hepatoma cell apoptosis.

Methods: H4IIE liver cells were treated with palmitic acid, linoleic acid, or both with or without the calciumspecific chelator BAPTA-AM after which the expression of proteins associated with endoplasmic reticulum (ER) stress, apoptosis, caspase-3 levels, and calcium flux were measured.

Results: Palmitic or linoleic acid $(250 \mu \mathrm{M})$ induced H4IIE cell apoptosis, which required calcium flux but not caspase-3. Apoptosis was not observed when cells were co-treated with linoleic acid (125 $\mu \mathrm{M})$ and palmitic acid $(250 \mu \mathrm{M})$. Importantly, the release of cytochrome $\mathrm{C}$ from mitochondria into cytoplasm during cell apoptosis was specifically detected only when linoleic acid $(125 \mu \mathrm{M})$, but not palmitic acid $(250 \mu \mathrm{M})$, was added to the cells. Depletion of intracellular calcium flux by the calcium-specific chelator, BAPTA-AM, abolished linoleic acid-induced apoptosis. Moreover, in the presence of BAPTA-AM, expression of the unfolded protein response (UPR)-associated genes, CHOP, GRP78, and GRP94, was induced by linoleic acid, but not palmitic acid.
\end{abstract}

Conclusions: The results suggest that linoleic acid promotes cell apoptosis through the release of cytochrome $C$, only if the intracellular calcium flux is unperturbed and intact. These results confirm that ER stress contributes to fatty acid-induced liver cell apoptosis.

Keywords: Nonalcoholic fatty liver disease, Palmitic, Linoleic, Endoplasmic Reticulum Stress, BAPTA-AM; Thapsigargin

\section{Background}

Nonalcoholic fatty liver disease (NAFLD) is a multifactorial disease [1] that manifests as symptoms, ranging from mild steatosis, to nonalcoholic steatohepatitis and cirrhosis in the liver. Although NAFLD affects millions of people worldwide, its etiology remains unclear. However, hepatic inflammation and degeneration induced by the deposition of lipid droplets in the organ has been established as one of the major causes of the disease [1-3]. In particular, certain saturated fatty acids, such as palmitic acid, can induce endoplasmic reticulum (ER) stress and apoptosis in rat and human liver cell lines [4-9], leading to inflammation and/or degeneration in

\footnotetext{
* Correspondence: rongliangxue@126.com

'Anesthesia Department, the Second Affiliated Hospital of Xi'an Jiaotong University, No. 157, West 5th Road, Xi'an, Shaanxi Province-710004, China Full list of author information is available at the end of the article
}

the liver. This hypothesis was further supported by the observation that ER stress and apoptosis could be induced by palmitic acid in both primary cells and cell lines derived from mice and rats $[10,11]$.

Overconsumption of fat-containing foods is one of the major contributors to obesity and NAFLD. Dietary fatty acids in the liver may provoke ER stress and apoptosis in liver cells, but controversy remains over the differential effects exerted by saturated and unsaturated fatty acids with respect to liver damage. For example, Vecchini et al. [12] demonstrated hepatoma cell apoptosis in response to unsaturated $\alpha$-linolenic acid, and a later study indicated that a polyunsaturated fatty acids can augment the effects of a saturated fatty acids on inducing ER stress and apoptosis in liver cells [8]. However, other evidence strongly suggested that unsaturated fatty acids can protect against saturated fatty acid-mediated
C Biomed Central

(c) 2012 Zhang et al; licensee BioMed Central Ltd. This is an Open Access article distributed under the terms of the Creative Commons Attribution License (http://creativecommons.org/licenses/by/2.0), which permits unrestricted use, distribution, and reproduction in any medium, provided the original work is properly cited. 
ER stress and apoptosis in the kidney [13], fibroblasts [14], liver cells [7], and macrophages [15].

The biological basis for why saturated fatty acids are often lipotoxic whereas unsaturated fatty acids appear to be protective is poorly understood and requires clarification [16]. Our previous studies show that unsaturated fatty acid alpha-linoleic acid could reduced ER stressmediated apoptosis of saturated fatty acids palmitic acid and stearic acid lipotoxicities in primary rat liver cells $[17,18]$. Whether this phenomenon also exists in liver tumor cells is unknown.

A previous study by Wei et al. [7] showed that the exposure of rat hepatoma H4IIE cells to saturated fatty acids (e.g., palmitic acid and, to a lesser extent, stearic acid) reduced thapsigargin-sensitive calcium stores and increased the expression of biochemical markers of ER stress, leading to cell death. However, co-incubation of the cells with oleic acid-and, to a lesser extent, linoleicprevented the effects induced by palmitic acid. Linoleic acid, a polyunsaturated essential fatty acid, is abundant in diets that have been associated with the pathogenesis of NAFLD. The objective of this study was to determine the underlying mechanism of the interaction between linoleic acid and palmitic acid on ER stress and apoptosis in rat hepatoma H4IIE liver cells.

\section{Materials and Methods}

\subsection{Materials and reagents}

Palmitic and linoleic acids, thapsigargin, and other reagents were purchased from Sigma-Aldrich (St. Louis, MO) unless otherwise specified. The calcium-specific chelator BAPTA-AM (1,2-bis-(O-aminopenoxy)-ethane$N, N, N$, $N^{\prime}$-tetraacetic acid tetraacetoxymethyl ester) was obtained from Biomol International Lp/Enzo Life Sciences (Plymouth Meetings, PA).

\subsection{Cell culture}

Rat hepatoma H4IIE liver cells (American Type Culture collection, Manassas, VA) were cultured in Dulbecco's Modified Eagle's Medium supplemented with $10 \%$ fetal bovine serum, penicillin, and streptomycin sulfate. This medium was defined as the control medium (LG), and was prepared with or without $125 \mu \mathrm{M}$ or $250 \mu \mathrm{M}$ palmitic acid or linoleic acid as previously described [8]. Briefly, fatty acids were complexed to bovine serum albumin at a 2:1 molar ratio by treating a $20 \mathrm{mM}$ solution of fatty acid in $0.01 \mathrm{M} \mathrm{NaOH}$ at $70^{\circ} \mathrm{C}$ for $30 \mathrm{~min}$. Addition of $1 \mathrm{~N} \mathrm{NaOH}$ was used to promote solubilization. Fatty acid soaps were then complexed with fatty acid-free BSA in phosphate-buffered saline to achieve the appropriate 2:1 (fatty acid-to-albumin) molar ratio. The fatty acid concentrations selected (125 and $250 \mu \mathrm{M})$ were based on those reported by Wei et al. [7]. The cells were treated for 16 hours in each condition. In calcium flux study, the cells were treated with indicated acids in the absence or presence of $10 \mu \mathrm{M}$ calcium-specific chelator BAPTA-AM for 16 hours.

\subsection{RNA isolation and real-time RT-PCR}

Total RNA was extracted with TRIzol reagent (Invitrogen, Carlsgbad, CA) according to the manufacturer's instructions. A 5- $\mu$ l sample of DNase-treated RNA was used for reverse transcription with Superscript II RNa$\mathrm{seH}$ and random hexamers. Real-time polymerase chain reaction amplification of the transcribed CDNA was performed with the IQ-SYBR green master mix (BioRad, Hercules, CA). The sequences of the six primer sets were as previously reported (Supplemental Table One [9]).

The PCR efficiency was between $90 \%$ and 105\% for all primer and probe sets and linear over five orders of magnitude. The specificity of products generated for each set of primers was examined for each fragment by melting curve and gel electrophoresis. Reactions were run in triplicate, and data were calculated as the change in cycle threshold $(\triangle \mathrm{CT})$ for the target gene relative to the $\Delta \mathrm{CT}$ for $\beta_{2}$-microglobulin according to the procedures of Muller et al. [19].

\subsection{Western blot analysis}

Western blot analysis was performed as described previously [9]. Primary antibodies used were against GRP78 (Stressgen, Victoria, BC, Canada), GRP94 (Santa Cruz Biotechnology, Santa Cruz, CA), CHOP (Santa Cruz Biotechnology, Santa Cruz, CA), and $B$-actin (Sigma Chemical Company, St. Louis, MO). Expression levels of the respective proteins were determined with horseradish peroxidase-conjugated secondary antibodies (GE Healthcare, Piscataway, NJ) and enhanced chemiluminescence reagent (Pierce, Rockford, IL). Band densities were quantified with a UVP BioImaging system (Upland, $\mathrm{CA}$ ) and normalized against $\beta$-actin.

\subsection{Measuring caspase-3 activity}

Caspase- 3 activity was measured according to a colorimetric assay that measures the extent of cleavage of a caspase-specific peptide derivatized with p-nitroalanine, such that upon proteolysis, the chromophore is released and the concentration is measured spectrophotometrically. The assay was performed according to the manufacturer's instructions (R\&D Systems, Inc.). Briefly, cells stained with Trypan blue were counted by hemocytometer, and approximately $10^{6}$ cells were used in each assay. Cells were pelleted $(250 \times \mathrm{g}$ for 10 minutes), the supernatants were discarded, and the pellets were lysed. Protein content within lysates was estimated using the BCA Protein Assay (Pierce, Rockford, IL), and enzymatic reactions for caspase activity were carried out in 96-well 
flat bottom microplates. Following incubation with the Caspase- 3 colorimetric substrate (DEVD-pNA), the extent of proteolysis was measured from the colorimetric intensity as read by a microplate reader at 405 $\mathrm{nm}$. Control reactions were run without cell lysate and without substrate.

\subsection{Analysis of apoptosis and cytochrome $C$ assay}

Cells were harvested in PBS and collected by centrifugation as described previously [7], and the cytochrome C content in the post-mitochondrial supernatant was determined by ELISA using a kit (Invitrogen, Carlsbad, CA). Cell death was evaluated with the Cell Death Detection ELISA kit (Roche Diagnostics, Penzberg, Germany), which uses mouse monoclonal antibodies directed against DNA and histones.

\subsection{Measurement of calcium flux}

Changes in calcium flux were determined with the Fluo4 NW calcium assay kit (Molecular Probes, Eugene, OR). Briefly, cells were loaded with Fluo-4 NW in the presence of probenecid (4-dipropylamino-sulfonyl benzoic acid), and the fluorescence (494 nm excitation, 516 $\mathrm{nm}$ emission) was measured over the time points indicated.

\subsection{Statistical Analysis}

Means and standard deviations were calculated for each group. Comparisons were performed by ANOVA with post-hoc comparison adjusted by the Bonferroni method. Data were analyzed with SAS 9.0 (SAS Institute Inc., Cary, NC). Values of $P<0.05$ were considered statistically significant.

\section{Results}

\subsection{Effects of fatty acids on H4IIE cell apoptosis, caspase} 3 activity and calcium level

The apoptotic response of rat liver H4IIE cells to the fatty acid treatments was first confirmed by measurement of cytoplasmic histone-associated DNA fragments, as shown in Figure 1A. Treatment of cells for $16 \mathrm{~h}$ with thapsigargin $(2 \mu \mathrm{M})$, palmitic acid $(250 \mu \mathrm{M})$, or linoleic acid $(250 \mu \mathrm{M})$ significantly increased cell death compared with the untreated control cells $(P<0.05)$. Notably, linoleic acid induced significantly greater apoptosis than the same concentration of palmitic acid at the same time point $(P<0.05)$. Interestingly, the combination of PA and $125 \mu \mathrm{M}$ LA but not $250 \mu \mathrm{M}$ LA significantly decreased apoptosis in comparison to PA treatment alone. However, no significant changes in caspase- 3 activity were observed in response to fatty acid treatments (Figure 1B).

Because caspase- 3 activity remained unaltered in response to fatty acid treatment, ER calcium flux was analyzed to determine if it was involved in the apoptosis observed in Figure 1A. As shown in Figure 1C, increased calcium flux was observed in cells treated with palmitic acid $(250 \mu \mathrm{M})$ for $16 \mathrm{~h}$. However, linoleic acid $(250 \mu \mathrm{M})$ decreased calcium flux at $16 \mathrm{~h}$ whereas no differences were observed with palmitic and linoleic acid cotreatments (Figure 1C).

\subsection{Effects of palmitic and linoleic acids on UPR- associated gene expression}

The unfolded protein response (UPR) is the main pathway related to ER stress [20]. Therefore, the expression of genes involved in the UPR, ATF4, CHOP, GADD34, GRP78, and GRP94, was assessed after fatty acid treatment for $16 \mathrm{~h}$ (Figure 2 and 3). Significantly increased ATF4, CHOP, GADD34, and GRP78 mRNA expression was observed upon treatment with thapsigargin $(2 \mu \mathrm{M})$; no changes in GRP94 expression were observed (Figure 2E). Changes in the H4IIE cells were observed upon cotreatment with palmitic and linoleic acid. Significantly increased CHOP mRNA expression was observed upon cotreatment $(125 \mu \mathrm{M})$ whereas GRP78 mRNA expression was significantly decreased with cotreatment at both concentrations (Figure 2B and 2D). However, these changes in the H4IIE cells were not observed at the protein level for either of these genes (Figure 3A and 3B). Increased GRP78 and GRP94 protein expression (Figure $3 \mathrm{~B}$ and $3 \mathrm{C}$, respectively) were also observed upon thapsigargin treatment; however, no changes in $\mathrm{CHOP}$ protein expression were observed (Figure $3 \mathrm{~A}$ ). In contrast, treatment of H4IIE cells with $250 \mu \mathrm{M}$ palmitic or linoleic acid alone failed to alter the mRNA or protein expression of any of these genes. A representative Western blot for each protein after the indicated treatments is shown in Figure 3D.

\subsection{Role of calcium in fatty acid-induced liver cell apoptosis and ER stress}

The role of intracellular calcium in fatty acid-induced H4IIE cell apoptosis and ER stress was analyzed using the highly specific calcium chelator, BAPTA-AM (10 $\mu \mathrm{M}$; Figure 4). As shown in Figure 4A, BAPTA-AM treatment alone for $16 \mathrm{~h}$ did not alter H4IIE cell apoptosis. However, it did significantly reduce the cell death induced by both palmitic and linoleic acids (Figure $4 \mathrm{~A}$ ).

Cytochrome $\mathrm{C}$ levels were also determined after treatment with fatty acids; palmitic acid $(250 \mu \mathrm{M})$ did not affect its level in the absence or presence of BAPTAAM (Figure 4B). However, cytochrome C levels were increased significantly upon treatment with linoleic acid $(125 \mu \mathrm{M})$, which was reversed with BAPTA-AM (Figure 4B; $P<0.05)$. Thus, saturated palmitic acid and unsaturated linoleic acid may mediate their pathologic effects 


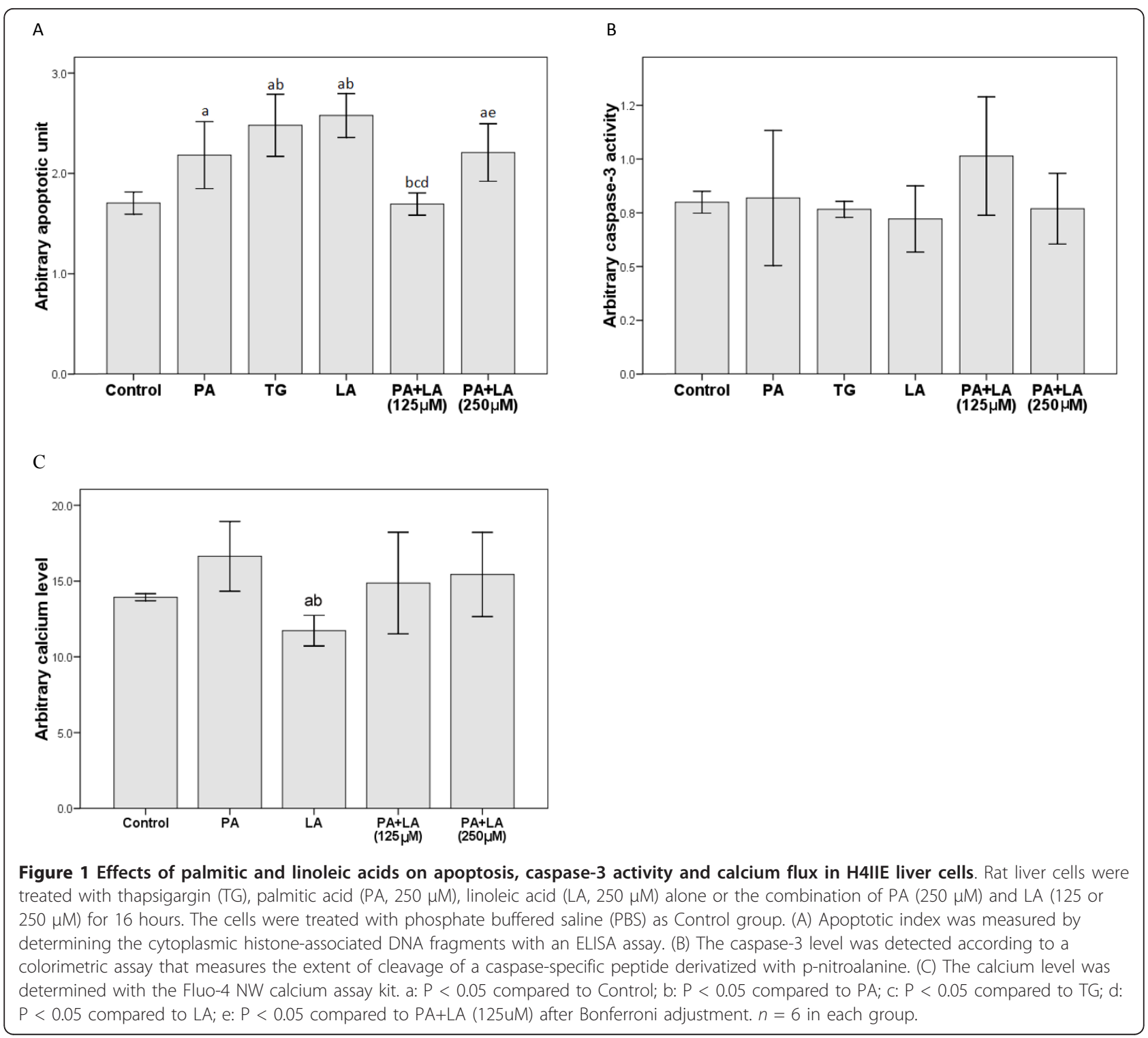

in the liver through different calcium-dependent apoptotic pathways (i.e., linoleic acid, but not palmitic acid, requires calcium flux and the release of cytochrome $\mathrm{C}$ to induce cell apoptosis).

Consistent with this hypothesis, cells treated with BAPTA-AM and $125 \mu \mathrm{M}$ linoleic had increased CHOP, GRP78, and GRP94 mRNA expression as compared to those treated with linoleic acid alone; this was not observed for palmitic acid (Figure 4C-E). The mRNA expression levels for CHOP and GRP94 were lower in cells treated with linoleic rather than palmitic acid (Figure $4 \mathrm{C}$ and $4 \mathrm{E}$ ). These results again indicate that calcium is required for the cytochrome $\mathrm{C}$-dependent apoptosis promoted by the expression of certain genes important in UPR.

\section{Discussion}

The objective of this study was to examine the hypothesis that palmitic acid induces ER stress and cell death in hepatoma cells, which is inhibited by linoleic acid. Thus, the effects of these fatty acids, alone and in combination, on apoptosis, caspase- 3 activity, cytochrome $\mathrm{C}$ levels, ER stress, calcium flux changes, and mRNA and protein expression of ER stress-associated genes were examined in rat hepatoma H4IIE cells.

Linoleic acid induced significantly more apoptosis than palmitic acid, which is consistent with an earlier report in smooth muscle cells in which palmitic and linoleic acids were assessed at physiological mixtures (300-900 $\mu \mathrm{M})$ over 24-72 h [4]. Because plasma FFA and TG in rodents reach approximately $500 \mu \mathrm{M}$, future 

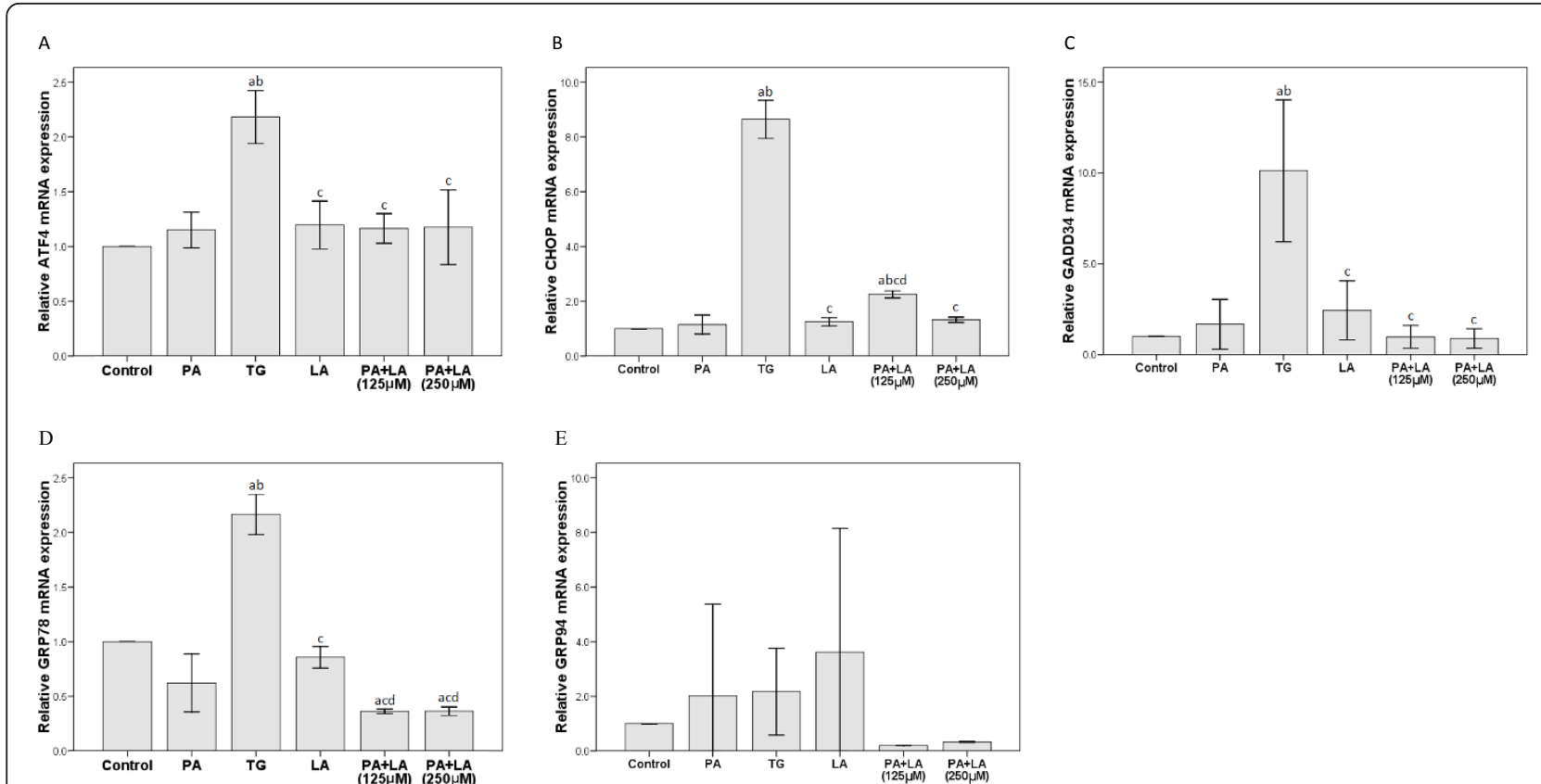

Figure 2 Effects of palmitic and linoleic acids on the expression of UPR-associated genes in mRNA level. The tumor cells were treated with TG, PA $(250 \mu \mathrm{M})$, LA $(250 \mu \mathrm{M})$ alone or PA+LA $(125 \mu \mathrm{M}$ or $250 \mu \mathrm{M})$ for $16 \mathrm{hr}$. The cells were treated with PBS as Control group. The levels of the respective mRNAs for (A) ATF4, (B) CHOP, (C) GADD34, (D) GRP78, and (E) GRP94 were determined by real-time RT-PCR relative to $\beta 2$ microglobulin. a: $\mathrm{P}<0.05$ compared to Control; b: $\mathrm{P}<0.05$ compared to $\mathrm{PA}$; $\mathrm{C}: \mathrm{P}<0.05$ compared to TG; $\mathrm{d}$ : $\mathrm{P}<0.05$ compared to LA after Bonferroni adjustment. $n=3$ in each group.

analyses of the effects of linoleic and palmitic acid will include higher concentrations.

Both palmitic and linoleic acid evoked a significant elevation of calcium flux (ER stress) at $16 \mathrm{~h}$, which is in relatively good agreement with one previous report [7]). Fatty acid treatment had no effect on caspase-3 activity, indicating that apoptosis of H4IIE cells induced by either fatty acid was probably not mediated through this pathway. These results contrasted with previous reports, which demonstrated that saturated fatty acids increased caspase- 3 and caspase- 9 activity [8], and that DCP-LA, a derivative of linoleic acid, can protect neurons from oxidative stress-induced apoptosis by inhibiting caspase- 3 and -9 activation [21]. Further experiments on the role of other caspases, such as caspase-12 [20,22], will be pursued. The apoptotic pathway activated by palmitic and linoleic acid is therefore distinct from that inhibited by metformin, the antidiabetic drug reported to inhibit palmitate-induced apoptosis via activation of caspase-3 [5]. Like unsaturated fatty acids, metformin also blocked the induction of ER stress proteins, and may protect hepatocytes from death induced by saturated fatty acids [5].

Previous investigators have reported that treating a range of cell-types with unsaturated fatty acids protected the cells against increased apoptosis and lipotoxicity caused by saturated fatty acids, including palmitic acid
$[10,13,14,16,21,23]$. In contrast, we observed that apoptosis was greater in cells treated with $250 \mu \mathrm{M}$ linoleic acid alone than with the same concentration of palmitic acid. Furthermore, a protective effect against palmitic acid-induced apoptosis by linoleic acid was observed only at $125 \mu \mathrm{M}$, but not $250 \mu \mathrm{M}$, which is inconsistent from our previous reports in primary liver cells $[17,18]$. Use of a hepatoma cell line in this study versus primary rat liver cells in previous studies $[17,18]$ may account for these discrepancies.

In the present study, caspase- 3 was not involved in mediating fatty acid-induced apoptosis, and direct measurements of calcium flux indicated no involvement in apoptosis. However, the addition of the calcium specific chelator, BAPTA-AM, prevented apoptosis induced by palmitic acid alone, as well as palmitic acid plus $250 \mu \mathrm{M}$ linoleic acid, suggesting that calcium does indeed play a role in the apoptotic response. More importantly, cytochrome $\mathrm{C}$ release was detected only when unsaturated linoleic acid $(125 \mu \mathrm{M})$, but not the saturated palmitic acid $(250 \mu \mathrm{M})$, was added to the cells, and depletion of the intracellular calcium pool abolished this linoleic acid-mediated effect. The effects on cytochrome $\mathrm{C}$ release were again in sharp contrast to previous reports in which increased cytochrome $\mathrm{C}$ in post-mitochondrial supernatants were detected after treatment with palmitic acid [7]. Thus, liver damage may be caused by different 


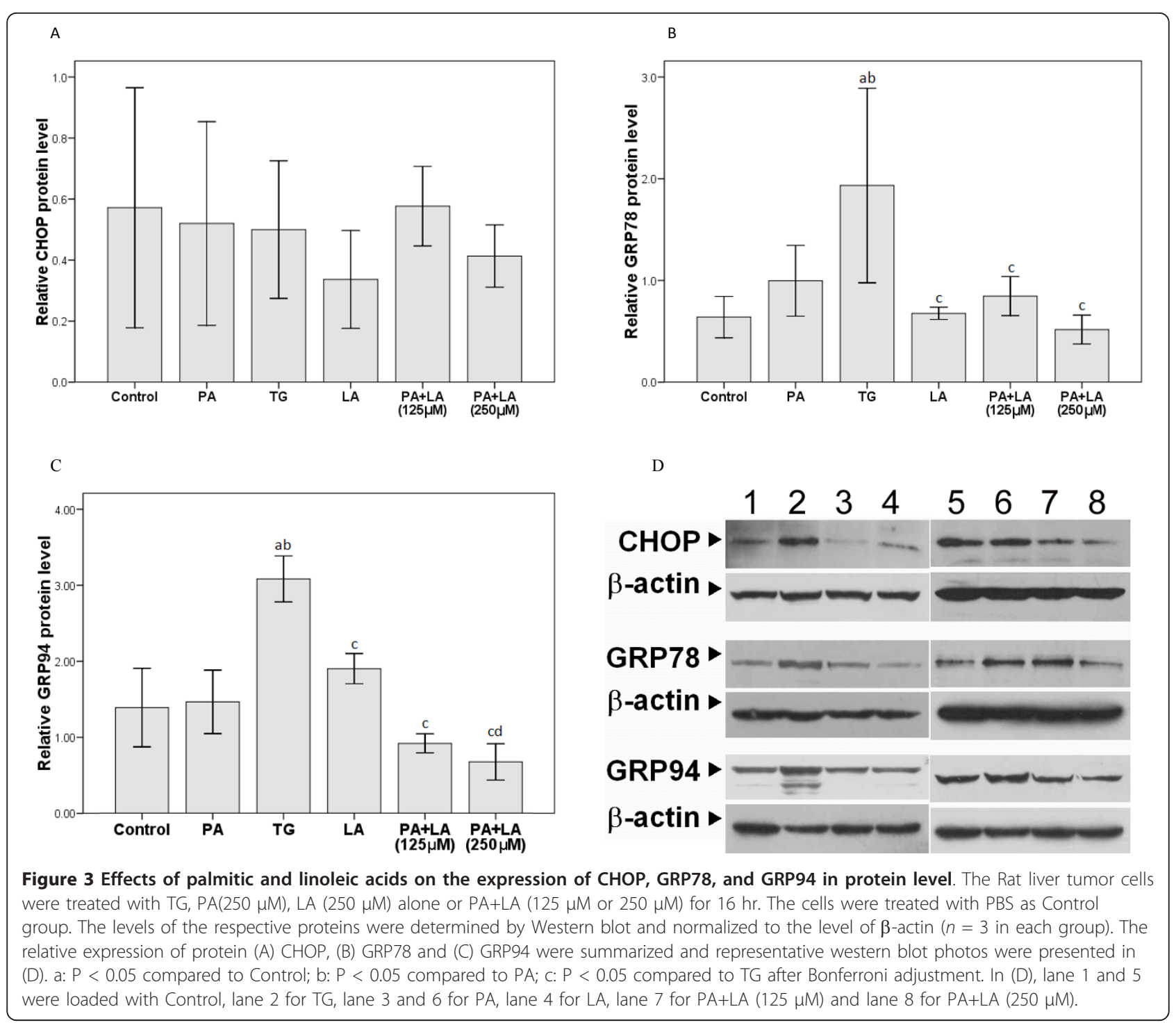

fatty acids through alternate apoptotic pathways, and whether or not linoleic acid can protect the liver from palmitic acid-induced apoptosis depend on the balance of influences exerted by the different apoptotic/ER stress pathways. This may resolve the controversies stemming from the observation that dietary saturated and unsaturated fatty acids provoke ER stress and apoptosis differently in liver cells [7,8,12-14].

Monitoring changes in the mRNA levels of UPRrelated genes provided a direct way of measuring the effects of palmitic and linoleic acid on ER stress. Wei et al. [7] reported increased expression of the UPR-associated genes, ATF4, CHOP, GADD34, and GRP78 after incubation with $250 \mu \mathrm{M}$ palmitic or unsaturated (oleic) acid after only $6 \mathrm{~h}$. Wei et al. [7] also reported that 125 $\mu \mathrm{M}$ oleic acid (an unsaturated FA) reversed the apoptotic and ER stress effects induced by $250 \mu \mathrm{M}$ palmitic acid, in direct agreement with the data presented here using linoleic acid. Ishiyama et al. [15] reported that oleic acid and linoleic acid (at $200 \mu \mathrm{M}$ ) suppressed the upregulation of the oxidized LDL receptor- 1 by palmitic acid $(200 \mu \mathrm{M})$ or by thapsigargin $(2 \mu \mathrm{M})$, reducing the uptake of oxidized LDL by macrophages and alleviating ER stress. Thus, unsaturated FA can ameliorate the apoptotic and ER stress effects of palmitic acid or other saturated FA.

Studies investigating the effects of FA upon apoptosis and ER stress in cells are often inconsistent; some inconsistencies are due to different incubation times, FA concentration, total dosage and exposure time, and cell lines. For example, Karaskov et al. [23] reported that $1 \mathrm{mM}$ palmitic acid upregulated some but not all UPR related genes in a pancreatic $ß$-cell line, where levels of ATF4 and CHOP increased, but GRP78 levels 


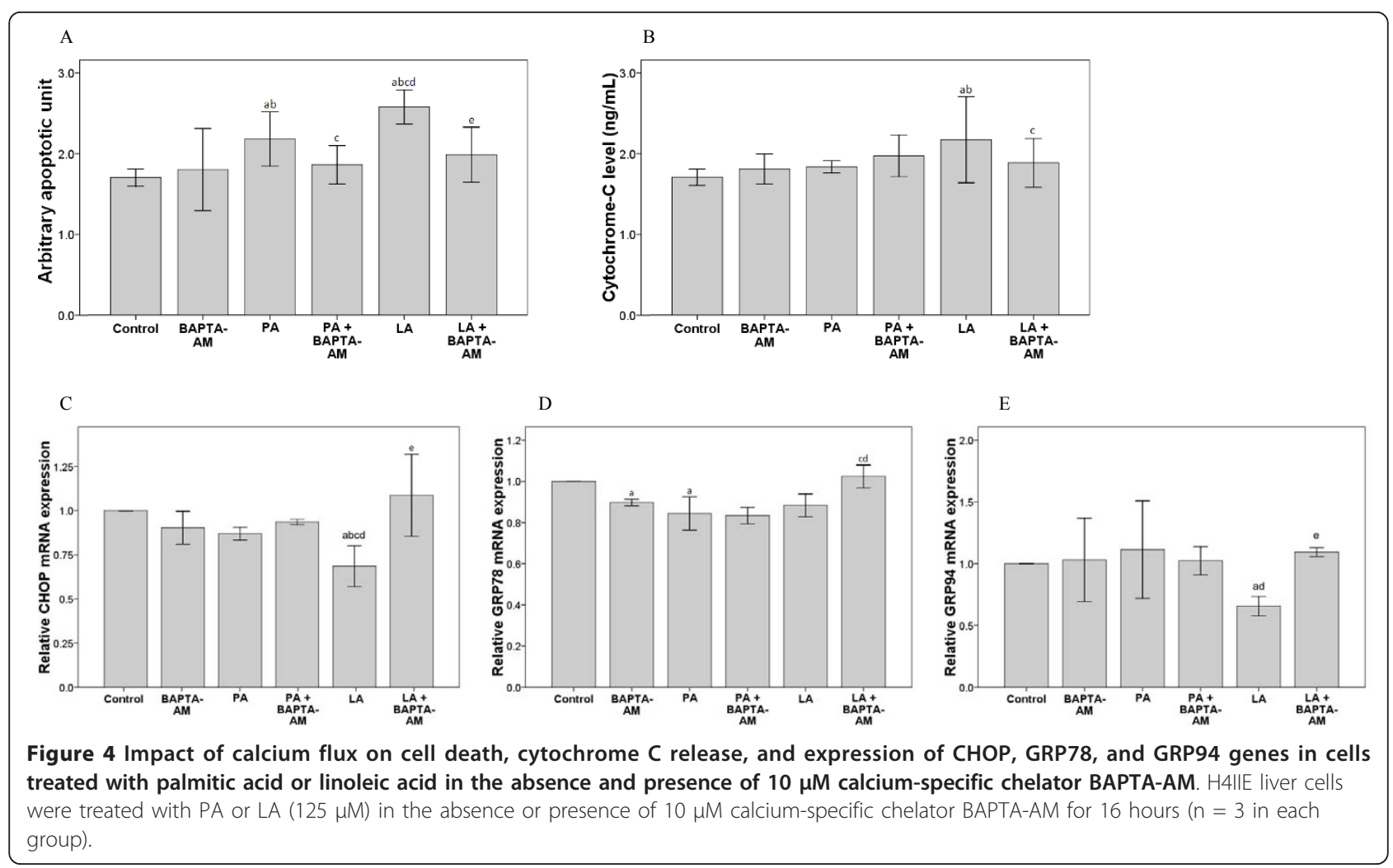

remained unchanged, which are in contrast to our results. The present study also analyzed another important UPR-related gene, GRP94 [20], for its FAinduced gene expression profile. The gene expression induced by either FA was mild, if not suppressed, and the elevated levels were similar. Simultaneous treatment with both FA revealed the induction and suppression of the CHOP and GRP94 gene expression levels, respectively, which reached significance when liver cells were co-incubated with $125 \mu \mathrm{M}$ of linoleic acid and $250 \mu \mathrm{M}$ palmitic acid; further increasing the linoleic acid concentration to $250 \mu \mathrm{M}$ reversed the suppressive effects of $125 \mu \mathrm{M}$ linoleic acid on mRNA expression. However, similar changes in protein concentration were not observed. The concentrationdependence of the linoleic acid-mediated suppression may reflect other activities for this FA in addition to the anti-lipotoxic role described here, such as generating mutagenic metabolites capable of damaging DNA in response to oxidative stress [14].

Overexpression of GRP78 can provide resistance to cells against apoptosis induced by thapsigargin [24], and so it is significant that cells treated with thapsigargin contained higher levels of expressed GRP78 after $16 \mathrm{~h}$ in the present study. Increased GRP78 expression may help cells adapt against ER stress induced by thapsigargin. GRP78 has even been reported to protect Mouse
MIN6 pancreatic ß-cells from palmitate-induced apoptosis [25].

In summary, the effects of palmitic and linoleic fatty acids on H4IIE cell apoptosis and ER stress were investigated. The results strongly suggest that both palmitic and linoleic acid required the flux of calcium to mediate ER stress. Furthermore, cytochrome C, but not caspase3, was selectively involved in FA-induced cell apoptosis. Among the genes that are important for UPR, it is likely that CHOP and GRP94 play a role in mediating the physiologic phenomenon. In contrast with previous studies $[8,9]$, caspase-3 seemed to play no role in FAinduced liver apoptosis, but this and other conclusions drawn from this study warrant further investigation.

\section{Author details}

${ }^{1}$ Anesthesia Department, the Second Affiliated Hospital of Xi'an Jiaotong University, No. 157, West 5th Road, Xi'an, Shaanxi Province-710004, China. ${ }^{2}$ Department of Respiration, the Second Affiliated Hospital of Xi'an Jiaotong University, No. 157, West 5th Road, Xi'an, Shaanxi Province-710004, China.

\section{Authors' contributions}

YZ conceived, designed and coordinated the work, as well as prepared the manuscript. RX was involved in the co-design of the work as well as the draft of the manuscript. ZZ, HS and XY carried out analytical work and contributed in drafting the manuscript. All authors read and approved the final manuscript.

\section{Competing interests}

The authors declare that they have no competing interests. 
Received: 15 November 2011 Accepted: 5 January 2012

Published: 5 January 2012

\section{References}

1. Byrne CD: Fatty liver: role of inflammation and fatty acid nutrition. Prostaglandins Leukot Essent Fatty Acids 2010, 82:265-271.

2. Solís Herruzo JA, García Ruiz I, Pérez Carreras M, Muñoz Yagüe MT: Nonalcoholic fatty liver disease. From insulin resistance to mitochondrial dysfunction. Rev Esp Enferm Dig 2006, 98:844-874.

3. Straub BK, Schirmacher P: Pathology and biopsy assessment of nonalcoholic fatty liver disease. Dig Dis 2010, 28:197-202.

4. Artwohl M, Lindenmair A, Roden M, Waldhäusl WK, Freudenthaler A Klosner G, llhan A, et al: Fatty acids induce apoptosis in human smooth muscle cells depending on chain length, saturation, and duration of exposure. Atherosclerosis 2009, 202:351-362.

5. Kim DS, Jeong SK, Kim HR, Kim DS, Chae SW, Chae HJ: Metformin regulates palmitate-induced apoptosis and ER stress response in HepG2 liver cells. Immunopharmacol Immunotoxicol 2010, 32:251-257.

6. Pfaffenbach KT, Gentile CL, Nivala AM, Wang D, Wei Y, Pagliassotti MJ: Linking endoplasmic reticulum stress to cell death in hepatocytes: roles of C/EBP homologous protein and chemical chaperones in palmitatemediated cell death. Am J Physiol Endocrinol Metab 2010, 298:E1027-E1035.

7. Wei Y, Wang D, Gentile CL, Pagliassotti MJ: Reduced endoplasmic reticulum luminal calcium links saturated fatty acid-mediated endoplasmic reticulum stress and cell death in liver cells. Mol Cell Biochem 2009, 331:31-40

8. Wei Y, Wang D, Pagliassotti MJ: Saturated fatty acid-mediated endoplasmic reticulum stress and apoptosis are augmented by trans-10, cis-12-conjugated linoleic acid in liver cells. Mol Cell Biochem 2007, 303:105-113.

9. Wei Y, Wang D, Topczewski F, Pagliassotti MJ: Saturated fatty acids induce endoplasmic reticulum stress and apoptosis independently of ceramide in liver cells. Am J Physiol Endocrinol Metab 2006, 291:E275-E281.

10. Guo W, Wong S, Xie W, Lei T, Luo Z, et al: Palmitate modulates intracellular signaling, induces endoplasmic reticulum stress, and causes apoptosis in mouse 3T3-L1 and rat primary preadipocytes. Am J Physiol Endocrinol Metab 2007, 293:E576-E586.

11. Ricchi M, Odoardi MR, Carulli L, Anzivino C, Ballestri S, Pinetti A, Fantoni LI, et al: Differential effect of oleic and palmitic acid on lipid accumulation and apoptosis in cultured hepatocytes. I Gastroenterol Hepatol 2009, 24:830-840.

12. Vecchini A, Ceccarelli V, Susta F, Caligiana P, Orvietani P, Binaglia L, Nocentini $G$, et al: Dietary alpha-linolenic acid reduces COX-2 expression and induces apoptosis of hepatoma cells. J Lipid Res 2004, 45:308-316.

13. Katsoulieris E, Mabley JG, Samai M, Green IC, Chatterjee PK: alpha-Linolenic acid protects renal cells against palmitic acid lipotoxicity via inhibition of endoplasmic reticulum stress. Eur J Pharmacol 2009, 623:107-112.

14. Beeharry N, Lowe JE, Hernandez AR, Chambers JA, Fucassi F, Cragg P Green $\mathrm{MH}$, et al: Linoleic acid and antioxidants protect against DNA damage and apoptosis induced by palmitic acid. Mutat Res 2003, 530:27-33.

15. Ishiyama J, Taguchi R, Akasaka Y, Shibata S, Ito M, Nagasawa M, Murakami K: Unsaturated FAs prevent palmitate-induced LOX-1 induction via inhibition of ER stress in macrophages. J Lipid Res 2011, 52:299-307.

16. Nolan CJ, Larter CZ: Lipotoxicity: why do saturated fatty acids cause and monounsaturates protect against it? J Gastroenterol Hepatol 2009, 24:703-706.

17. Zhang Y, Yang X, Shi H, Dong L, Bai J: Effect of a-linolenic acid on endoplasmic reticulum stress-mediated apoptosis of palmitic acid lipotoxicity in primary rat hepatocytes. Lipids Health Dis 2011, 10:122

18. Zhang Y, Dong L, Yang $X$, Shi H, Zhang L: a-Linolenic acid prevents endoplasmic reticulum stress-mediated apoptosis of stearic acid lipotoxicity on primary rat hepatocytes. Lipids Health Dis 2011, 10:81

19. Muller PY, Janovjak H, Miserez AR, Dobbie Z: Processing of gene expression data generated by quantitative real-time RT-PCR. Biotechniques 2002, 32:1372-1374, 1374, 1378-1379.

20. Liao $N$, Hendershot $L$ : The unfolded protein response: contributions to development and disease. In Cell Stress Proteins. Edited by: Calderwood SK. New York: Kluwer Academic/Plenum Publishers; 2007:57-88.
21. Yaguchi T, Fujikawa H, Nishizaki T: Linoleic acid derivative DCP-LA protects neurons from oxidative stress-induced apoptosis by inhibiting caspase-3/-9 activation. Neurochem Res 2010, 35:712-717.

22. Minamino T, Kitakaze M: ER stress in cardiovascular disease. J Mol Cell Cardiol 2010, 48:1105-1110.

23. Karaskov E, Scott C, Zhang L, Teodoro T, Ravazzola M, Volchuk A: Chronic palmitate but not oleate exposure induces endoplasmic reticulum stress, which may contribute to INS-1 pancreatic beta-cell apoptosis. Endocrinology 2006, 147:3398-3407.

24. Lai E, Bikopoulos G, Wheeler MB, Rozakis-Adcock M, Volchuk A: Differential activation of ER stress and apoptosis in response to chronically elevated free fatty acids in pancreatic beta-cells. Am J Physiol Endocrinol Metab 2008, 294:E540-E550

25. Laybutt DR, Preston AM, Akerfeldt MC, Kench JG, Busch AK, Biankin AV, Biden TJ: Endoplasmic reticulum stress contributes to beta cell apoptosis in type 2 diabetes. Diabetologia 2007, 50:752-763.

\section{doi:10.1186/1476-511X-11-1}

Cite this article as: Zhang et al: Palmitic and linoleic acids induce ER stress and apoptosis in hepatoma cells. Lipids in Health and Disease 2012 $11: 1$

\section{Submit your next manuscript to BioMed Central and take full advantage of:}

- Convenient online submission

- Thorough peer review

- No space constraints or color figure charges

- Immediate publication on acceptance

- Inclusion in PubMed, CAS, Scopus and Google Scholar

- Research which is freely available for redistribution 